\title{
Breve aproximación a L'école des filles y Le portier des chartreux (dos ejemplos de novelas libertinas de los siglos XVII y XVIII)
}

\author{
Claudia RUIZ GARCÍA \\ Universidad Nacional Autónoma de México
}

Acercarse a la novela libertina francesa implica forzosamente revisar los diferentes matices que adquiere el término "libertin" a lo largo de los siglos XVI, XVII y XVIII. Durante el siglo XVI aparece la voz "libertisme", bañada de una carga despectiva. Este vocablo es utilizado por primera vez por Calvino para designar a los disidentes anabaptistas, provenientes de un grupo protestante de la región de Flandes, considerados como enemigos comunes de los católicos y protestantes. Jean-Claude Margolin, en su artículo "Libertins, libertinisme et 'libertinage' au XVIe siècle", advierte que los términos empleados por Calvino conllevan juicios de valor porque, para este partidario de la reforma de la Iglesia, los libertinos sólo eran "des extravagants, des hommes qui ont perdu le sens commun, des insensés, des fous, mais des fous dangereux pour eux-mêmes et pour les autres. Il [fallait] donc les combattre, car leur secte [était] pernicieuse".'

Cinco años después de la publicación del tratado de Calvino, intitulado Contre la secte phantastique et furieuse des libertins qui se nomment spirituelz, Guillaume Farel, en 1550, retoma algunas de las críticas enunciadas anteriormente por el reformador suizo y ataca la postura religiosa de los anabaptistas, acusándolos de haber inventado "une belle doctrine pour putains et ruffians". ${ }^{2}$ El sentido del término comienza a ampliarse y se convierte en sinónimo de heterodoxo, materialista, ateo o todo vocablo que sirva para designar a los partidarios de la construcción del pensamiento arreligioso y antirreligioso. Finalmente, en el transcurso de los últimos cin-

' Jean-Claude MARGolin, "Libertins, libertinisme et 'libertinage' au Xvle siécle", en Aspects du libertinisme au XVIe siècle, p. 5. Trad.: "Unos extravagantes, hombres que han perdido el sentido común, insensatos, locos, pero locos peligrosos para sí mismos y para otros. Entonces [era] necesario combatirlos, porque su secta [era] perniciosa".

${ }^{2}$ Apud. Estudio preliminar de Les romans libertins du XvIIIe siècle de Raymond Trousson, p. II. Trad.: "Una bella doctrina para putas y rufianes". 
cuenta años de ese siglo, el término fue asimilado por la parte adversaria de los protestantes - los católicos-, quienes se sirvieron de éste para denunciar la estrecha conexión que existía entre la manía de interpretar con cierta libertad algunos dogmas religiosos y la depravación de las costumbres, incluyendo en un solo grupo a los ateos, escépticos o pirrónicos y a los epicúreos. ${ }^{3}$

Al llegar al siglo XVII nos encontramos con parte de esta tradición que no deslinda fronteras al interior de término, pero hoy día, gracias a los incomparables trabajos de René Pintard, es posible distinguir más nítidamente dos vertientes. Por un lado, la conformación de un grupo de filósofos y hombres de ciencia que Pintard identifica como "libertins érudits" o "libertinage érudit" $y$, por otro lado, un grupo que reúne a los partidarios de un desenfreno de las costumbres. El primero sirve para nombrar a los sabios y filósofos que rechazan los dogmas, y que únicamente aceptan aquello que puede ser claramente establecido y admitido por medio de la razón. Dentro de este grupo, a manera de ejemplo, podríamos situar a Cyrano de Bergerac, quien

${ }^{3}$ En esta categoria cabrian escritores de la talla de Rabelais y de Montaigne. Al primero se le clasificó en su tiempo como a un autor irreverente, obsceno, escatológico; incluso entre los círculos letrados se le reprochó, como fue el caso del poeta Nicolas Bourbon, de escribir únicamente bagatelas. Michel de Montaigne, por su parte, aunque siempre se declaró católico convencido, sus Ensayos pasaron a formar parte de los libros incluidos en el Índice, documento de la Iglesia católica donde se incorporaban los textos que, por contener ideas peligrosas y pecaminosas, quedaban prohibidos y obligados a ser distribuidos de manera clandestina y subterránea. Conocido es el pasaje de los "Caníbales" de los Ensayos, donde Montaigne pone en tela de juicio las prácticas mentales y religiosas de su tiempo. Allf nos dice: "Je ne suis pas marri que nous remarquons l'horreur barbare que qu'il y a en une telle action, mais oui bien de quoi jugeant bien de leurs fautes, nous soyons si aveugles aux nôtres. Je pense qu'il y a plus de barbarie à manger un homme vivant qu'à le manger mort, à déchirer par tourments et par gênes un corps encore plein de sentiment, le faire rôtir par le menu, le faire mordre et meurtrier aux chiens et aux pourceaux (comme nous l'avons non seulement lu, mais vu de fraîche mémoire, non entre des ennemis anciens, mais entre des voisins et des concitoyens, et, qui pis est, sous prétexte de piété et de religion), que de le rôtir et manger après qu'il est trépassé". Libro primero, capitulo XXXI, pp. 310-311. Trad.: "No dejo de reconocer la barbarie y el horror que supone comerse al enemigo [práctica de los habitantes de una region de Canadál, mas si me sorprende que comprendamos y veamos sus faltas y seamos ciegos de reconocer las nuestras. Creo que es más bárbaro comerse a un hombre vivo que comérselo muerto; desgarrar por medio de suplicios y tormentos un cuerpo todavia lleno de vida, asarlo lentamente, y echarlo luego a los perros o a los cerdos; esto, no sólo lo hemos leido, sino que lo hemos visto recientemente, y no es que se tratara de antiguos enemigos, sino de vecinos y conciudadanos, con la agravante circunstancia de que para la comisión de tal horror sirvieron de pretexto la piedad y la religión. Esto es más bárbaro que asar el cuerpo de un hombre y comérselo después de muerto". 
morirá víctima de un supuesto accidente, maquinado por sus enemigos. Estando en vida se propuso difundir, a partir de unos textos que podían pasar como novelas de aventuras, una serie de ideas que, en su conjunto, atacaban a la ciencia, la filosofía y la religión de su tiempo. ${ }^{4}$

Françoise Charles-Daubert considera que la voz "libertin" en el siglo XVII también "désigne essentiellement celui qui s'affranchit des règles de la morale, des dogmes et des croyances religieuses, pour se laisser aller à tous les dérèglements qui lui suggère sa fantaisie". 5 Y es dentro del grupo de escritores del siglo que se inclinan por un júbilo de la transgresión donde debe situarse el texto L'école des filles ou la philosophie des dames.

Este texto está considerado como la primera obra verdaderamente escandalosa de la época de Luis XIV ${ }^{6}$ y se le ha atribuido a Michel Millot, de quien se colgó una efigie cuando dicho documento comenzó a circular y sus ejemplares fueron quemados al pie de la horca. Al editor, Jean L'Ange, que se había encargado de imprimir el libro, se le expulsó de Paris durante tres

${ }^{4}$ Cyrano de Bergerac nunca vio su obra impresa. Antes de morir confió su manuscrito al más fiel y seguro de sus amigos, Le Bret, para que se encargara de imprimirlo; sin embargo, esta tarea resultaba muy penosa para el amigo porque él conocia los escritos de Cyrano, los que siempre calificó de peligrosos, además únicamente contaba con treinta y nueve años, gozaba de un puesto como abogado en el Parlamento y estaba preparándose para recibir el sacerdocio. Situación privilegiada que no podía arriesgar sólo porque había hecho una promesa a su amigo. No obstante, se decidió a cumplir con su palabra, pero antes de publicar el Viaje a la luna pensó que era pertinente censurar ciertas partes, señalando con puntos suspensivos los pasajes cortados. Además cambió el título por el de Historia cómica y durante los siglos XVII, XVIII y XIX se difundió, con gran éxito, el texto mutilado. Fue a partir de 1919 en Alemania y de 1921 en Francia que se pudo, después de una ardua tarea de reconstrucción, publicarlo de manera integral, reincorporando los pasajes que Le Bret habia considerado perniciosos. Es muy interesante seguir de cerca la historia de la recepción del texto de Cyrano durante el siglo XVIII y XIX porque, a pesar de no contener parte de lo que ahora se considera como esencial de la obra, este Viaje a la luna se anticipa -incorporando algunas ideas de la novela del inglés Godwin El hombre en la luna- a todos los relatos interplanetarios de finales del siglo XIX y principios del XX.

5 "Le 'libertinage érudit': problèmes de définition", p. 13. Trad.: "Designa esencialmente a aquel que traspasa las reglas de la moral, de los dogmas y de las ciencias religiosas, para dejarse llevar por cualquier desenfreno que le sugiera su fantasía".

- Jean Jacques Pauvert dice que este texto es la primera obra erótica francesa escrita en prosa, distribuida de manera clandestina y condenada por la audacia de su contenido. Pauvert reconoce que no debe hacerse a un lado la importancia de la poesía licenciosa francesa y de los "fabliaux" que desde la Edad Media configuran la tradición del relato atrevido y picante; sin embargo, L'École des filles es para este crítico la primera puesta en escena "prosaica" francesa de retozos y jugueteos amorosos. Anthologie historique des lectures érotiques, p. 740. 
años. Jean-Jacques Pauvert señala que, durante el proceso contra el texto, Jean L'Ange denunció en primer lugar al conde de Cramail como un posible autor y después al conde de Etelan, ambos ya fallecidos en el momento del juicio. Al final, presionado por el interrogatorio mencionó a Millot, declarando que éste era el autor o tal vez el traductor de la obra. Así, la circulación del texto se redujo a ediciones piratas provenientes de Holanda. A pesar de esta limitante el libro gozó de un gran éxito. Alexandrien advierte que

[...] en 1661, on en trouva un exemplaire chez le surintendant Fouquet au moment de son arrestation; après les rééditions de 1665 et de 1668, le livre circula secrètement en France. Le 19 novembre 1687, Bussy-Rabutin raconta à Mme de Sévigné qu'on découvrit L'École des filles dans la chambre des filles d'honneur de la Dauphine; Louis XIV en fut si furieux qu'il les renvoya toutes. Mais Samuel Pepys parla avec enthousiasme, dans son Journal, de la traduction anglaise de ce livre. Plus tard, le Régent Philippe d'Orléans fit graver vingtquatre planches pour illustrer L'École des filles, qu'il goûtait particulièrement.?

Este texto es la primera novela de aprendizaje libertino. Está conformado por una serie de diálogos entre dos primas. En el primero, Suzanne instruye a su prima Fanchon de dieciséis años, quien no sabe si debe perder su virginidad. En el segundo, esta última cuenta a su supuesta maestra - Suzanne- las experiencias vividas a raíz de la pérdida de su doncellez. A lo largo de estos diálogos se establece un intercambio de recetas, técnicas, prácticas; en suma, se define el placer sexual y se delimita un "saber o conocimiento libertino" que nos hace recordar un poco los diálogos del Aretino ${ }^{8} \mathrm{y}$ en los que se representa "un travail de subversión et de dévalorisation sur une

7 AleXandrien, Histoire de la littérature érotique, p. 124. Trad.: "En 1661, se encontró un ejemplar de $L$ 'École des filles en casa del supertintendente Fouquet en el momento de su arresto; después circuló de manera clandestina en Francia en 1665 y 1668. El 19 de noviembre de 1687 Bussy-Rabutin relató a Madame de Sévigné que se habia descubierto $L$ 'École des filles en los aposentos de las damas de honor de la esposa del hijo del rey; Luis XIV, furioso, despidió a todas. Sin embargo, Samuel Pepys, en su Diario, comentó con cierto entusiasmo la traducción al inglés de ese libro. Más tarde, Felipe de Orléans mandó grabar veinticuatro láminas para ilustrar $L ' E ́$ cole des filles, texto que en particular le complacía".

${ }^{8}$ Sus Ragionamenti están elaborados en forma de diálogo. En ellos, una de sus protagonistas, Nanna, mujer con una larga experiencia en placeres de la carne, platica con su amiga Antonia sobre el terrible dilema de escoger para su hija el matrimonio, el convento o la prostitución. Antonia le dice que para ayudarle a resolver el enigma debe 
dispersion discursive dominante, à savoir le néo-platonisme, plus généralement le dualisme chrétien, mais aussi bien toute la sublimation idéalisante comme par exemple le courant pétrarquiste". ${ }^{9}$ En un pasaje Franchon pregunta a su prima qué es el amor. Suzanne le responde que es el deseo de una mitad para servir o unirse a su otra mitad; sin embargo, después de una larga explicación la causa del amor es reducida al simple placer corporal.

En suma, puede decirse que $L$ 'École des filles es una novela dialogada que, a pesar de insistir sobre cierta libertad de las costumbres, resulta menos escandalosa por su erotismo que por su paganismo. La culpabilidad cristiana ha quedado fuera. Todo está permitido, todo es vivido de manera natural y ningún acto adquiere el tinte de perverso. Después de la enseñanza y de la aplicación práctica de esta teoría del amor y del placer se presenta, a manera de colofón, cierta filosofía libertina. Casi al finalizar el texto nos encontramos con el siguiente diálogo:

FRANCHON. Ma cousine, quand je vous écoute, ces leçons sont bien éloignées de celles que ma mère fait à sa fille quand elle lui prêche la vertu et l'honnêteté.

SUZANNE. Ainsi va le monde, ma pauvre cousine: le mensonge gouverne la vérité, la raison veut reprendre l'expérience, et les sottises s'érigent en titres de bonnes choses. La virginité est une très belle chose en paroles et très laide en ses effets; au rebours, la paillardise n'a rien de plus hideux que le nom et rien de plus doux que les effets. Les gens mariés paillardent aussi bien que les autres, ils font toutes les mêmes actions et postures, et encore plus souvent que les garçons et les filles; les plus scrupuleux, c'est toujours le vit au con qu'ils agissent, et la cérémonie ne change rien au mystère d'amour. ${ }^{10}$

contarle su propia experiencia. A lo largo del diálogo Nanna hace un recuento con lujo de detalle de las bacanales que conoció en el convento, después de cómo su madre la instruyó para hacerse pasar como una mujer virgen durante su primera noche del día de su matrimonio y, finalmente, cómo, quedando viuda, se instaló en un burdel. En otro de los diálogos Nanna revelará a su hija una serie de secretos para engatusar a los hombres con mentiras, rechazos calculados y delicadezas fingidas.

9 Jean-Pierre DUBost, Estudio introductorio de Euvres érotiques du Xvlle siècle, p. 12. Trad.: "Un trabajo de subversión y de desvalorización sobre una dispersión discursiva dominante, a saber el neoplatonismo, más de manera general el dualismo cristiano, pero también cualquier forma de sublimación típica del idealismo, por ejemplo la corriente petrarquista".

${ }^{10}$ Op. cit. pp. 285-286. Trad.: "Franchon. Prima mia, cuando os escucho, me parecen esas lecciones tan alejadas de las que mi madre da a su hija cuando le predica la virtud y la honestidad. SUZANNE. Así va el mundo, pobre prima mia: la mentira gobierna la verdad, la razón quiere retomar la experiencia, y las tonterias se erigen como 
Aquí la pintura sistemática de un libertinaje queda ya definida a partir del lugar central que ocupa la satisfacción del deseo carnal y que rechaza cualquier tipo de límite o coacción, perfilando lo que será en el siguiente siglo la "Edad de oro del libertinaje".

Durante el siglo XVIII Francia jugará un papel importante en la producción de literatura libertina o galante. La novela francesa de la época pretenderá convertirse en un estudio de las costumbres, revelando el mundo subterráneo de la sociedad y describiendo en particular lo que sucedía en los conventos, monasterios, pensionados y ministerios, identificados como verdaderos centros de lujuria y desenfreno. Dentro de este grupo de novelas cabe citar L'Histoire de Dom $B^{* * *}$, portier des Chartreux, conocida más bien como Le portier des Chartreux, obra que se le ha atribuido a JeanCharles Gervaise de la Touche, abogado del Parlamento de París. Es una de las novelas eróticas más conocidas y también una de las más leídas, "constamment réédité au long du siècle, ce livre eut un tel succès que Mme de Pompadour en possédait un exemplaire de l'édition de 1748, et que le marquis de Paulmy fit orner le sien de vingt-huit miniatures peintes sur vélin"," pero también se dice que es:

L'un des plus occultés: rares sont les écrivains, ou les lecteurs, qui y font explicitement référence. Le notaire qui dresse l'inventaire de la bibliothèque du marquis de Sade au Château Lacoste, le 12 avril 1769 , le classe dans la catégorie "romans libres" et le désigne pudiquement par les initiales: $P$... Ch..., sans nom d'auteur. Trop "libre" pour figurer explicitement dans la bibliothèque de l'auteur, le roman a plus de chance dans la fiction: Sade le cite explicitement dans l'Histoire de Juliette ou les prospérités du vice: fouillant, la bibliothèque d'un moine libertin, Juliette s'extasie sur la quantité de livres obscènes qu'elle contient, au nombre desquels figurent $L$ 'Académie des dames, l'Éducation de Laure et Thérèse philosophe. Mais le premier cité, celui qui retient son attention, c'est le Portier

titulares de algo bueno. La virginidad es muy bella como palabra y muy fea en sus efectos; por el contrario, la lujuria no tiene de repelente más que el nombre y nada de más dulce sino sus efectos. La gente casada se entrega a la lujuria al igual que los otros, realizan los mismos actos y posturas y todavia más que los chicos y las chicas; los más escrupulosos, es en función de su verga al coño que actúan y la ceremonia no altera en nada los misterios del amor".

$"$ Alexandrien, op. cit., p. 148. Trad.: "Constantemente reeditado a lo largo del siglo, este libro tuvo tal éxito que Madame de Pompadour poseía un ejemplar de la edición de 1748. El marqués de Paulmy mandó decorar el suyo con veintiocho miniaturas pintadas sobre papel vitela". 
des Chartreux, "production plus polissonne que libertine, et qui, néanmoins, malgré la candeur et la bonne foi qui y règnent, donna, dit-on, au lit de la mort, des repentirs de son auteur". ${ }^{12}$

Circuló de manera clandestina desde su aparición hasta mediados de los años sesentas del siglo XX. Este texto se inserta dentro de la tradición inaugurada por L'École des filles, pues se trata de una novela de iniciación o aprendizaje del personaje central, pero se distingue de aquélla porque el joven Saturnin se encarga de educarse a sí mismo y educar a Suzon no por medio de discursos sino más bien por medio de actos y experiencias comunes. El relato se construye primero a partir de una serie de juegos sexuales de sus padres; el joven los espía y después los hace descubrir a su supuesta hermana - Suzon-, iniciándose asi mutuamente a la sexualidad. De ser un simple espectador, Saturnin gradualmente llegará a conocer y experimentar todas las estrategias inimaginables para procurarse el mayor placer posible. En medio de este acelerado recorrido llegará a convertirse en un hombre de la Iglesia y, formando parte de ella, participará en orgías en un convento donde descubre a su verdadera madre, una religiosa que, junto con otras, se encargaban de curar a los padres del pecado de concupiscencia y que vivían escondidas en un lugar cerrado entre la biblioteca del convento y una capilla. Episodio de la historia, como muchos otros, que sirven como denuncia ante la moral relajada e hipócrita del clero de la época. En una de esas orgias conventuales el protagonista, al referirse a lo que allí experimentaba, advierte:

Toutes se mettaient nues et me présentaient la volupté dans tous les point de vue. [L'une d'elles] me faisait coucher par terre entre deux

12 Roger Bozzetto y Geneviève GoUBIER-Robert, Lecture du Portier des Chartreux, pp. 259-260. Trad.: "Es también uno de los más ocultados: pocos son los escritores, o los lectores que hagan referencia explícita del mismo. El notario que realizó el inventario de la biblioteca del marqués de Sade en el castillo de Lacoste el 12 de abril de 1769 lo clasifica dentro de la categoria de 'novelas libres' y lo nombra de manera púdica con las iniciales: $P$... Ch..., sin nombre de autor. Demasiado 'libre' para figurar de forma explícita en la biblioteca del autor, la novela corrió con más suerte dentro de la ficción: Sade lo cita abiertamente en la Histoire de Juliette ou les prospérités $d u$ vice. Juliette, al hurgar en la biblioteca de un monje libertino, se extasía ante la inmensa cantidad de libros obscenos que contiene y en la que figuran l'Académie des dames, l'Éducation de Laure y Thérèse philosophe. Pero el primero que cita, aquel que capta su atención, es el Portier des Chartreux, 'producción más licenciosa que libertina, y que, sin embargo, a pesar del candor y de la buena fe que contiene, se dice, que provocó, en el lecho de muerte, el arrepentimiento de su autor'" 
chaises, et, mettant ensuite un pied sur l'une et un pied sur l'autre, elle s'accroupissait et son con se trouvait perpendiculairement à mes yeux. Dans cette situation, elle travaillait avec un godemiché pendant qu'une autre, placée devant moi, foutait de toutes ses forces avec le plus vigoureux de nos moines [...] Toutes étaient nues, toutes se grattaient, toutes déchargeaient, mes mains, mes cuisses, mon ventre, ma gorge, mon vit, tout était inondé, je nageais dans le foutre. ${ }^{13}$

Este pasaje anuncia el tipo de situaciones que se encontrarán en las novelas del marqués de Sade. Catherine de Vulpillières señala que la mayoría de los "ingredientes" sadianos están allí presentes, es decir, las orgías, la sodomía, el dolor, el incesto y los términos obscenos. ${ }^{14}$ Sin embargo, en este texto nunca se persigue la sumisión y el placer a partir del sufrimiento del otro. Por el contrario, el placer es siempre gozoso. Se intenta llegar a una situación ideal en donde todos aquellos que participan de la ceremonia amorosa y sexual reciben la parte de felicidad que les corresponde. Sin embargo, también se castigan los excesos. Al final de esta historia Saturnin, después de la muerte de la que siempre pensó que era su hermana -Suzon-, descubre que está infectado de sífilis y que deben amputarle la causa de su mal. En ese momento afirma:

Je ne souhaitais plus que la mort. J'avais perdu le pouvoir de jouir de la vie. J'aurais voulu me cacher éternellement ce que j'avais été. Je ne pouvais penser sans horreur à ce que j'étais. Le voilà donc, disais-je au fond de mon cœur, le voilà cet infortuné Père Saturnin, cet homme si chéri des femmes! Il n'est plus. Un coup cruel vient de lui enlever la meilleure partie de lui même. J'étais un héros, et je ne suis plus qu'un...! Meurs! Meurs, malheureux, meurs! Peux-tu survivre à cette perte? Tu n'es plus qu'un eunuque. ${ }^{15}$

${ }^{13}$ Op. cit. pp. 198-199. Trad.: "Todas se desnudaban y me mostraban la voluptuosidad desde cualquier ángulo. [Una de ellas] me hacía acostarme sobre el piso entre dos sillas, $y$, colocando enseguida un pie sobre una de éstas y el otro pie sobre la otra, se ponía en cuclillas y su cono se mostraba ante mis ojos de forma perpendicular. En esta posición, manipulaba un vibrador, mientras que otra, colocada frente a mí, cogia con todas sus fuerzas con el más vigoroso de los monjes. [...] Todas estaban desnudas, todas se chupaban, todas se desahogaban, mis manos, mis muslos, mi vientre, mi pecho, mi verga, todo quedaba inundado, yo nadaba en medio de esperma".

14 "Ses ancêtres les pornographes", p. 54.

15 Op. cit. pp. 247-248. Trad.: "No deseaba más que la muerte. Había perdido el poder de gozar de la vida. Hubiera querido ocultarme eternamente lo que habia sido. No podía pensar sin horror en lo que era. En el fondo de mi ser me decía jaquí está este desventurado Padre Saturnin, este hombre tan querido de las mujeres! Ya no queda 
Este texto junto con el de $L$ 'École des filles están todavía muy lejos de los complejos andamiajes de la seducción que encontraremos posteriormente en Laclos y en el marqués de Sade, en donde el libertinaje se convierte en regla de vida, pero se distingue de los primeros por la forma en que lo imponen de manera maquiavélica $y$, a veces, diabólica a los otros protagonistas de la historia, reduciéndolos a convertirse en simples marionetas de sus deseos. En este tipo de libertinaje el papel de la seducción y del seductor es lo más importante, hay toda una construcción cerebral que no se encuentra en el otro. En los ejemplos que hemos mencionado se observa siempre una disposición incondicional de los cuerpos que se ofrecen y se entregan sin ninguna limitante y sin que jueguen, de manera decisiva, maquinaciones externas. Esto revela que el término "libertine" se aplica de manera indistinta para identificar a novelas licenciosas, eróticas y pornográficas. Sin embargo, a pesar de la imposibilidad de establecer criterios bien definidos para catalogar este tipo de texto, puede señalarse que hacia el fin del siglo XVIII queda claro que con Laclos ya puede hablarse de la realización más acabada de la literatura libertina, mientras que la obra de Sade ya no puede clasificarse dentro de esta categoría sino más bien en la de novela filosófica. Aspecto que abre otra línea de investigación.

\section{Bibliografía}

ALEXANDRIEN, Histoire de la littérature érotique. París, Seghers, 1989.

Charles-Daubert, Françoise, "Le 'libertinage érudit': problèmes de définition", en Libertinage et Philosophie au XVIle siècle. Saint-Étienne, Publications de l'Université de Saint-Étienne, 1996.

L'École des filles, en CEuvres érotiques du XVIIe siècle (L'Enfer de la Bibliothèque Nationale), t. 7. Est. prel. de Jean-Pierre DuBOST. París, Fayard, 1988.

Le portier des Chartreux. Est. prel. de Roger BOzzETTO y Géneviève GOUBIER-ROBERT. Arles, Actes Sud, 1993.

nada de él. Un golpe cruel acaba de quitarle la mejor parte de él mismo. ¡Yo era un héroe y no soy más que un...! ¡Muere!, ¡muere desdichado, muere! ¿Puedes sobrevivir a esta pérdida? No eres más que un eunuco". 
MARGOLIN, Jean-Claude, "Libertins, libertinisme et 'libertinage' au XVIe siécle", en Aspects du libertinisme au XVle siècle. Actes du Colloque International de Sommières. París, J. Vrin, 1974.

MONTAIGNe, Michel de, Essais I. Paris, Gallimard, 1965.

PAUVERT, Jean-Jacques, Anthologie historique des lectures érotiques. París, Stock/Spengler, 1995.

Romans libertins du XVIIle siècle. Est. prel. de Raymond TROUSSON. París, Robert Laffont, 1993.

VUlPILliÉRES, Catherine de, "Ses ancêtres les pornographes", en Europe. Sade. Le Grand guignol, núm. 835-838, nov.-dic., 1998. 